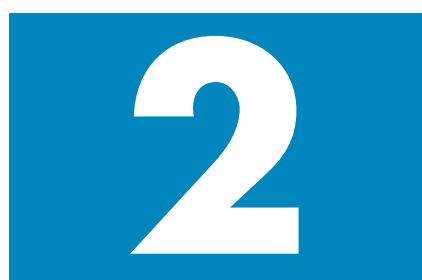

The first step in the

TNA is to ensure that the organisation has clear, focused business objectives. These should be agreed by top management (usually the owners in a dental practice and senior managers in other organisations) so that a clear idea of what the organisation is trying to achieve is understood by everyone in it.

In this part, we will discuss:

$\checkmark$ Identifying the objectives of the organisation

$\checkmark$ Appointing a training co-ordinator

$\checkmark$ Gathering information about the skills and abilities of the individuals that are needed now and will be needed in the future

$\checkmark$ Analysing that information

Identifying the gaps that exist between the current situation and what is/will be required

${ }^{1}$ Editor, British Dental Journal, 64 Wimpole Street, London W1G 8YS

${ }^{*}$ Correspondence to: Mike Grace

email:m.grace.bdj@bda-dentistry.org.uk REFEREED PAPER

(C) British Dental Journal

2001; 190: 524-526

\title{
Training needs analysis
}

\author{
M. Grace
}

training needs analysis (TNA) is the Aprocess of identifying the areas where both individuals and groups in an organisation would benefit from training in order to become more effective at achieving their own objectives and the objectives of the organisation.

A TNA involves five basic steps:

1 Identifying the objectives of the organisation

2 Appointing a training co-ordinator

3 Gathering information about the skills and abilities of the individuals that are needed now and will be needed in the future

4 Analysing that information

5 Identifying the gaps that exist between the current situation and what is/will be required

Each of these steps will be the subject of separate articles in the series. This second article looks at the whole process in outline and how a TNA links into the overall management of the organisation.

\section{The training plan}

Sometimes training is not really planned at all. Rather than being a proactive process training tends to be much more reactive. So, when a dental nurse is overheard on the telephone talking to a patient in an inappropriate manner some kind of training is then perceived as being needed, or may be provided there and then.

Most dental organisations have a basic plan for the clinical training staff, whether a dental nurse or junior clinician. However, an integrated training plan for the whole organisation may be lacking, leaving individuals to train others in a different fashion. In a group practice, for example, different dentists may well be providing very different levels of training for their dental nurses and even for the receptionists.

A training plan should prevent the confusion and ultimate inefficiency that tends to result from these ad hoc approaches, because a training plan should cover the whole organisation and should be consistent. That consistency starts with agreement of what the organisation is trying to achieve and what the priorities are at the moment.

Without this coherence training usually consists of individuals attending courses without the realization that it might be cheaper and more effective to engage a trainer to provide training within the organisation; or that money is being spent on training without any clear idea of what that training is trying to achieve. Different people will often be attending courses on the same subject unnecessarily, or going to courses in areas they are already competent at (but enjoy) or are interested in rather than in areas that are required in order for the organisation to meet its current objectives.

For example, imagine a dental practice that has decided that one of its main priorities at the moment is to increase gross income by $20 \%$. In order to achieve this objective everyone in the practice needs to be better at selling (improving patient acceptance of treatment plans that are clinically required). However the principal of the practice has received a brochure in the mail describing a local course on implant dentistry, and because this is an areas he is interested in he decides this course is exactly what is needed to help increase gross income. So the training budget (if there is one) is spent on the dentists attending this course rather than on everyone in the practice being trained (by an external trainer perhaps) in effective ethical selling.

\section{Clear objectives}

The first step in the TNA is to ensure that the organisation has clear, focused business objectives. These should be agreed by top management (usually the owners in a dental practice and senior managers in other organisations) so that a clear idea of what the organisation is trying to achieve is understood by everyone in it.

Usually this requires a mission statement (ideally a single sentence describing the chief aim of the organisation) and a set of strategic objectives. These objectives should tell everyone what the organisation thinks is important (its values) and what people should be focusing on (their jobs).

Based on these objectives it is possible to assess which areas of the overall business plan take priority at the moment, and which areas link with other areas. In our example of increasing gross income by $20 \%$ (which is a financial objective) we will obviously need to consider both selling and marketing objectives as well as possibly customer care and clinical care. There may well be topics in all of these areas that will need to be considered in order for the overall objective to be achieved.

\section{Appointing a training co-ordinator}

Even in the smallest organisation (such as a 


\section{continuing professional development}

dental practice containing one dentist and one receptionist/nurse) it is worth appointing a training co-ordinator.

The reason is that training needs to be part of someone's job. If it is not, it tends to get left out and that is one of the reasons why training is so often poorly planned and implemented.

Often the training co-ordinator can also be the training administrator (the person who books the courses or organises the training sessions). It can be the practice owner in a dental practice, or another member of staff. Whether the dentist takes on the role or it is delegated to someone else, commitment to organized training from 'top management' should be both visible and real. Time and money should be available to plan training for people according to their needs, and some involvement in the process is essential from the senior managers or owners.

\section{Gathering knowledge}

Once we are clear on our objectives and have a training co-ordinator appointed then we can begin to gather knowledge about what needs to be done, what is being done and how well the people involved are doing it.

We can divide the knowledge required into three areas:

1. What do people need to do in order that the objective is achieved?

2. What skills and knowledge do people already possess?

3. What skills and knowledge may be required in the future to continue to achieve future objectives?

Not all information will relate to training. For example, an objective to improve the décor of the patient's waiting area might well be important, but if an outside contractor is likely to be involved in providing the design and overseeing the implementation (or in the case of a small dental practice you are going to ask the receptionist's boyfriend to paint the waiting room) then no training is needed. However, sometimes a decision to involve outside help may well identify the need for training in order that the job can be properly commissioned. For example a marketing consultant may well be commissioned to increase the number of patients registering with the practice, but someone needs to understand how to ensure that the consultant is appropriately briefed.

There are a wealth of places where knowledge exists already or can be collected, and these will be covered in more detail in the fourth article in the series. Thus information can be gathered from CVs or application forms, job descriptions, staff and patient surveys, appraisal forms, interviews and self assessment forms. All of these will form a rich base from which an analysis can be made.

\section{Analysing the information}

This stage in the TNA is both stimulating and challenging. Analytical skills are required, and time to carry out the analysis is essential. If the organisation is to benefit from the effective use of resource in training then the person carrying out the TNA must be free to carry out a full and proper analysis. If not, the whole process is selfdefeating and often the process is blamed for failure rather than the lack of resource to carry it out properly.

The analysis should be answering the basic questions:

1. What gaps exist in both knowledge and ability of the current people in the organization to carry out their jobs now?

2. What gaps exist in both knowledge and ability of the current people in the organization to carry out their jobs in the future?

Thus the TNA allows for both current gaps relating to current job descriptions and possible gaps assuming some form of future development. For example a dental practice might be considering converting to a private capitation plan, which would require specialized training in the particular plan plus possible selling and marketing training (if applicable).

The analysis leads naturally into the final stage of the TNA.

\section{Identifying the gaps}

This final stage is really indistinguishable from the analysis in practice, but is given a separate heading because the way you actually record

\section{The analysis}

The analysis should be answering the basic questions:

I. What gaps exist in both knowledge and ability of the current people in the organization to carry out their jobs now?

2. What gaps exist in both knowledge and ability of the current people in the organization to carry out their jobs in the future?

the gaps can be important for the application of the TNA. Some method is required of recording those gaps in a way that facilitates the next stage following a TNA — drawing up a training plan.

\section{The training plan}

I started this article with a training plan, and I shall end with a training plan as well. This is because the whole point of the TNA is the actual planning and implementation of relevant training for the people in the organization.

Training plans should be documents the organisation uses to plan the training of everyone, costed out and budgeted for. They are working documents (in other words they keep 


\section{continuing professional development}

changing as events and circumstances change) and form the core of investment in the development of the people. They are also the end result of the TNA, as it is hardly worth investing all that time and effort in identifying training needs if nothing happens as a result.

\section{Conclusion}

This article has looked at the basics of a training needs analysis, considering the broad model itself. Thus a TNA is quite simply a way of identifying the existing gaps in either knowledge or ability of the people in the organization to carry out the tasks that enable them to do their jobs. The process assumes that the jobs people carry out have been defined in order that the business objectives of the organization will be achieved. Thus a training needs analysis will ensure people are better able to do their jobs because they have improved their knowledge and their skills in relevant areas. 